\title{
Influence of scaling effects on hub loads of a horizontal wind turbine
}

\author{
Romans Kazacoks* \\ *Wind Energy System CDT, Strathclyde University \\ romans.kazacoks@strath.ac.uk
}

Keywords: Fatigue, scaling, blade root loads

\begin{abstract}
Wind industry aims to generate more energy and reduce energy cost by increasing energy capacity of machines. As a result the loading scales up non-linearly. Nowadays there is a lack of studies of variation loads (specially fatigue ones) due to the up-scaling of wind turbine. This paper aims to generate a general fatigue load trends of several wind turbines, which are available to public. The accuracy of a controller of wind turbine models was investigated by checking blade root bending moments. Subsequently, fatigue loads were calculated based on these bending moments of blade root for each wind turbine model. The obtained results demonstrated possibility to generate the general load trend among the models. Additionally the blade root loading was divided into deterministic and stochastic parts, where each part was investigated the effect on fatigue loads. Moreover, a sensitivity study was performed to identify how much of influence does wind turbulence was on fatigue loads by the increasing reference turbulence intensity.
\end{abstract}

\section{Introduction}

European countries have set production energy targets which require increasing the energy output from renewables (including the wind energy sector) and decreasing the amount energy production from fossil fuel and nuclear. There are many limitations for wind farm sites in onshore. As a result the wind industry has moved to offshore to meet the set targets. The offshore market requires to up-scale wind turbines to decrease Euro/rated MW cost of a unit, because there is a strong believe that up-scaled machines can reduce operation \& maintenance cost and infrastructure cost [9]. It applies for 5MW rated power machine and above.

There are many software and techniques for calculating wind turbine loads. Nevertheless, there is a lack of information about load trends dependency from structural parameters,

\author{
Peter Jamieson ${ }^{\dagger}$ \\ † Wind Energy System CDT, Strathclyde University \\ peter.jamieson@strath.ac.uk
}

wind conditions and up-scale. However, several researches were performed in the past to investigate load trend of upscaled wind turbines.

The first research was presented by Chaviaropulos [1], where linear scaling technique was introduced. It is based on several assumptions:

- Tip speed of rotor blades is fixed.

- Dimensions of a wind turbine changes linearly.

As a result of these assumptions any innovation in design and material is neglected.

P. Jamieson $[2,8]$ introduced the load trends of wind turbines based on the commercial data. The provided data is scatter as there is large variety of different wind turbine designs in the wind industry.

The aim of this paper to investigate how loads (especially fatigue loads) change among the four wind turbines:

- 2 MW SuperGen (based on the NREL 2MW turbine)

- $3 \mathrm{MW}$ Generic

- 3.6 MW Generic,

- $5 \mathrm{MW}$ SuperGen (based on the NREL 5MW turbine)

The hub loads depend on the loads of blades. So the blade root loading will be investigated in this research.

\section{Background theory}

\subsection{Fatigue}

For the entire lifetime of a wind turbine it is under the pressure of constantly varying loads. These loads can be divided onto two different groups:

$>$ Deterministic loading:

- Steady loads

- Cyclic loads (blade weight (gravitational), wind shear, yaw error, tower shadow) 
- Impulsive loads (tower shadow)

Stochastic loading (turbulence)

These constantly varying loads have to be withstood by a wind turbine at each revolution of a rotor for the entire design life, which is usually 20 years and approximately 10 million revolutions $[3,4]$.

In this paper fatigue loads have been calculated using lifetime Damage Equivalent Loads (DELs) according to ICE standards $[5,6]$. Where, 10 minute simulation of each mean wind speed was combined with Weibull distribution probability of wind speed for the whole year. Rainflow counting method was used to obtain stress range and calculate number of cycles $[4,7]$.

\section{Approach}

The goal of this paper is to investigate and compare loads for $2 \mathrm{MW}, 3 \mathrm{MW}, 3.6 \mathrm{MW}$ and $5 \mathrm{MW}$. Subsequently, calculate fatigue loads by using the lifetime DELs and compare the gained data and generate fatigue loads trend. Additionally, generate and investigate the fatigue loads from deterministic and stochastic loading parts.

The applied load calculations are based on the design load case (DLC) 1.2, which covers all type of loads at power production conditions (in range from cut-in till cut-out mean wind speed), where a machine is connected to electrical load and is under above mentioned constantly varying loads. Normal turbulence condition was used, which is based at I A wind class and turbulence characteristic with turbulence reference intensity of 0.16 [6]. Moreover, the turbulence effect on the fatigue loads is investigated by increasing turbulence reference intensity from 0.16 to 0.2 . Other parameters unchanged.

\subsection{Models}

All models are three bladed, upwind, variable speed and pitch control wind turbines. The characteristic of each wind turbine is presented below.

\section{MW SuperGen:}

- Rated power - $2 \mathrm{MW}$

- Rotor diameter $-75 \mathrm{~m}$

- Rated speed - $12.6 \mathrm{~m} / \mathrm{s}$

- Transmission - Gearbox

\section{MW Generic machine:}

- Rated power-3 MW

- Rotor diameter $-100 \mathrm{~m}$

- Rated speed - $11.5 \mathrm{~m} / \mathrm{s}$

- Transmission - Gearbox
- $\quad$ Rated power - 3.6 MW

- Rotor diameter - $107 \mathrm{~m}$

- Rated speed - 12.4 m/s

- Transmission - Gearbox

\section{MW SuperGen:}

- Rated power - $5 \mathrm{MW}$

- Rotor diameter - $126 \mathrm{~m}$

- Rated speed - $11.3 \mathrm{~m} / \mathrm{s}$

- Transmission - Gearbox
- Cut-in speed - $4 \mathrm{~m} / \mathrm{s}$

- Cut-out speed - $25 \mathrm{~m} / \mathrm{s}$

- Tower height - $80 \mathrm{~m}$

- $\quad$ Tip speed ratio - 8
The following table presents power density of each wind turbine. Wind turbines 3.6 MW and 5 MW are offshore units, because power density of these units is large or equal to 400 watts per square meter. Consequently, $2 \mathrm{MW}$ and $3 \mathrm{MW}$ machines are onshore units

\begin{tabular}{|c|c|c|c|c|}
\hline Variables: & \multicolumn{5}{|c|}{ Wind Turbines } \\
\hline Power $(\mathrm{MW})$ & 2 & 3 & 3.6 & 5 \\
\hline Diameter $(\mathrm{m})$ & 75 & 100 & 107 & 126 \\
\hline Power density $\left(\boldsymbol{W} / \mathrm{m}^{2}\right)$ & 452.7 & 382.0 & 400.4 & 401.0 \\
\hline
\end{tabular}

Table 1: Power density of wind turbines

\section{Results}

Flap-wise and edge-wise bending moments of blade root are presented in the frequency domain by auto spectral density or power spectral density, because the output of the bending moment in the time domain is very unclear and difficult to interpret.

The aim of a controller of each wind turbine is to make sure that wind turbine works at optimum conditions, which means maximum energy capture and load alleviation. Additionally, control system has to avoid operating at the frequencies such as: flap-wise and edge-wise blade, fore-aft tower and generator speed. This paper considered only flap-wise and edge-wise blade structural frequencies. Other structural frequencies are not investigated in this paper.

\subsection{Flap-wise moment of blade root}

- Cut-in speed $-4 \mathrm{~m} / \mathrm{s}$

- Cut-out speed - $25 \mathrm{~m} / \mathrm{s}$

- Tower height- $65 \mathrm{~m}$

- $\quad$ Tip speed ratio -9.3

\subsection{MW Generic machine:}

- Cut-in speed - $4 \mathrm{~m} / \mathrm{s}$

- Cut-out speed $-25 \mathrm{~m} / \mathrm{s}$

- Tower height- $81.1 \mathrm{~m}$

- $\quad$ Tip speed ratio - 9
The flap-wise moment of blade root at $14 \mathrm{~m} / \mathrm{s}$ mean wind speed of four models is depicted by two figures. Figure 1 shows 2 MW SuperGen and 3 MW generic machines. Figure 2 depicts 3.6 MW generic and $5 \mathrm{MW}$ SuperGen machines.

The first detail has to be mentioned from figure 1 that the rotor speed of $2 \mathrm{MW}$ machine is faster than $3 \mathrm{MW}$ machine. As a result the rotor frequency of the $2 \mathrm{MW}$ unit is higher than the $3 \mathrm{MW}$ machine. It is presented by $1 \mathrm{P}$ peak of both models. The rest of peaks $(2 \mathrm{P}, 3 \mathrm{P}, 4 \mathrm{P}$, etc.) are harmonics of $1 \mathrm{P}$, which is the rotor frequency. There are some harmonic peaks in both models, which are higher than the previous ones. It is a result of the combination of a harmonic peak and 
a structural mode such as: the $2 \mathrm{MW}$ machine's $3 \mathrm{P}$ peak with the first flap-wise structural mode and the 3MW machine's $8 \mathrm{P}$ peak with the second structural mode (see figure 1).

The rotor speed of the $5 \mathrm{MW}$ unit is slower than the $3.6 \mathrm{MW}$ machine. It is shown by $1 \mathrm{P}$ peaks in figure 2 . Some harmonics are higher than the previous due to the same reason, which has been mentioned before.

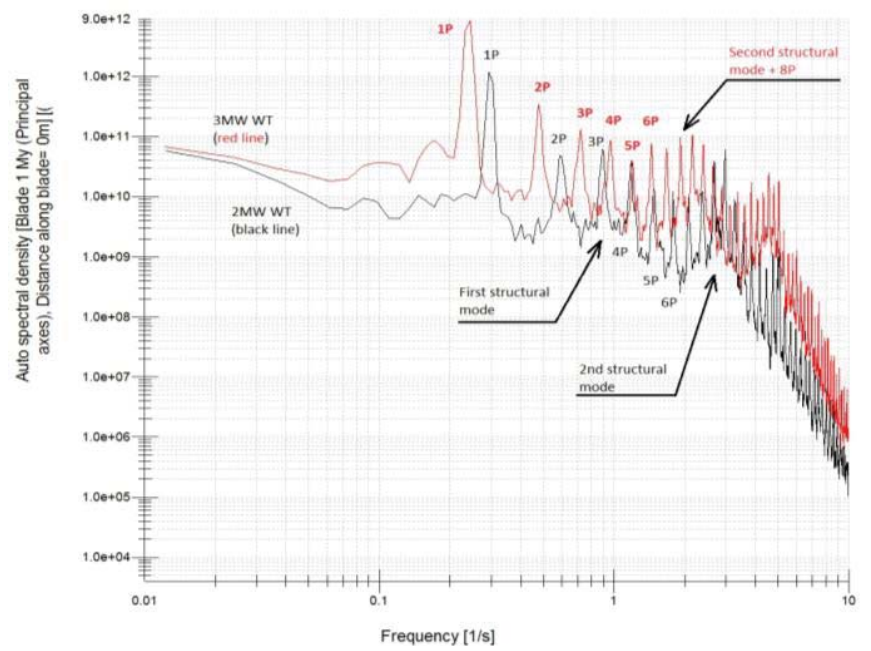

Figure 1: Flap-wise bending moment of blade root at 14 $\mathrm{m} / \mathrm{s}$ mean wind speed of $2 \mathrm{MW}$ SuperGen and $3 \mathrm{MW}$ generic unit

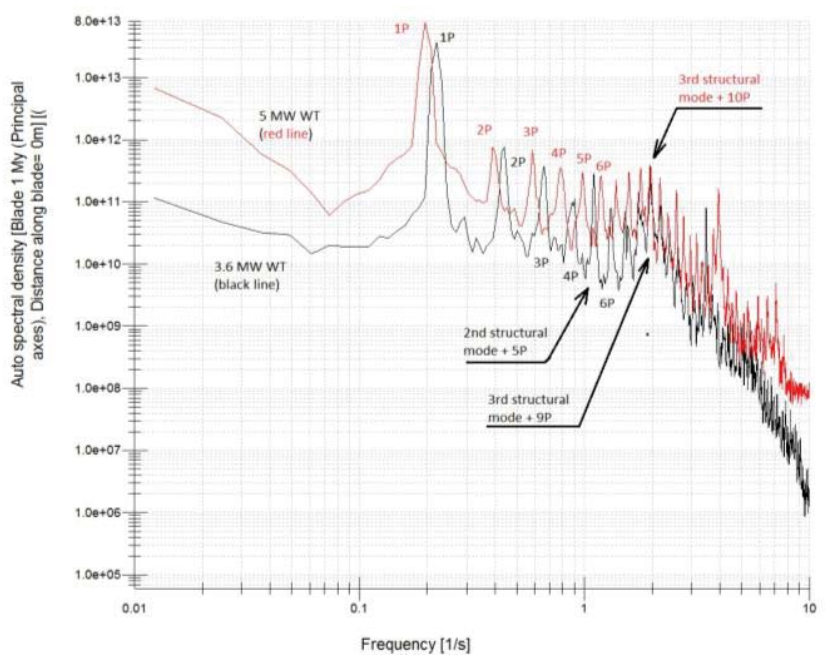

Figure 2: Flap-wise bending moment of blade root at 14 $\mathrm{m} / \mathrm{s}$ mean wind speed of 3.6 MW generic and $5 \mathrm{MW}$

SuperGen unit

\subsection{Edge-wise moment of blade root}

Once again the edge-wise bending moment of blade root at 14 $\mathrm{m} / \mathrm{s}$ mean wind speed of four models is presented by two figures in the same way as for the flap-wise bending moment. The 2 MW SuperGen and 3 MW generic machines are shown in figure 3. Figure 2 depicts $3.6 \mathrm{MW}$ generic and $5 \mathrm{MW}$ SuperGen machines.
The rotor frequency is shown by $1 \mathrm{P}$ and harmonics of it are $2 \mathrm{P}, 3 \mathrm{P}$ and etc. in figure 3 and 4 . It is same as in figure 1 and 2. There are different structural modes at flap-wise and edgewise bending moments because the edge-wise structural modes are presented by narrow spikes as these modes are not damped (see figure 3 and 4). The flap-wise structural modes are shown by a wide triangle shape (see figures 1 and 2), where the area beneath the triangle is the spent energy to damp the structural mode. There are two types of structural modes:

- $1^{\text {st }}$ one is damped as there is a wide triangle or a large swell (see figure 1 and 2).

- $\quad 2^{\text {nd }}$ type is un-damped one, which is high and narrow spike (see figure 3 and 4 )

The first evidence that the controller of each wind turbine works correctly is that the frequency of the edge-wise structural modes is higher than the flap-wise structural modes frequency.

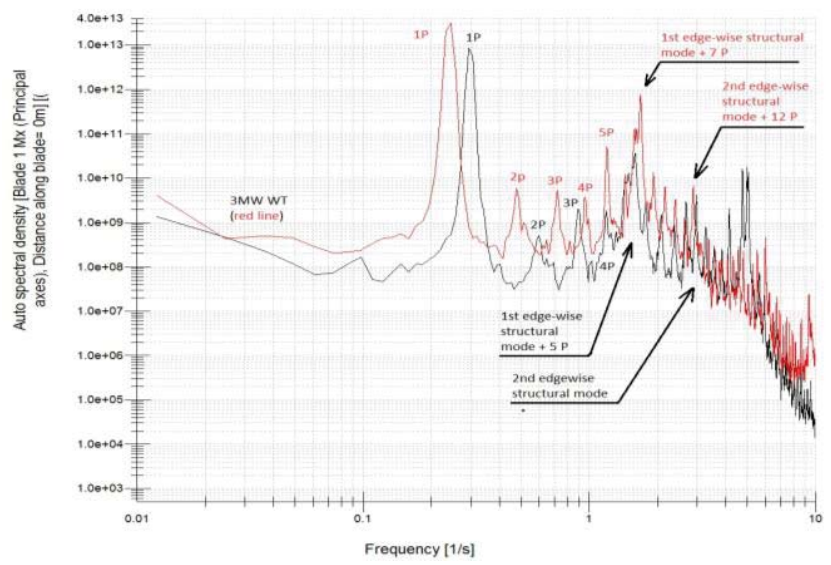

Figure 3: Edge-wise bending moment of blade root at 14 $\mathrm{m} / \mathrm{s}$ mean wind speed of $2 \mathrm{MW}$ SuperGen and $3 \mathrm{MW}$ generic unit

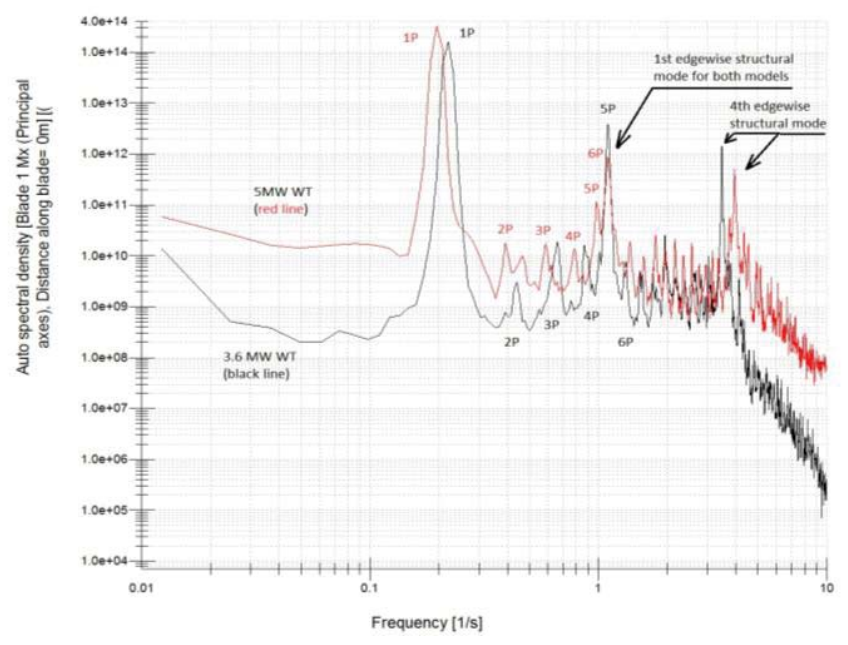

Figure 4: Edge-wise bending moment of blade root at 14 $\mathrm{m} / \mathrm{s}$ mean wind speed of 3.6 MW generic and $5 \mathrm{MW}$ SuperGen wind turbines. 
The flap-wise and edge-wise bending moment of blade root proved that the controller of each wind turbine works correctly, because there are no peaks which are higher than 1P peak (see figure 1,2,3 and 4).

\subsection{Lifetime Damage Equivalent Loads (DELs)}

In this section figures depict the flap-wise and edge-wise blade root moment lifetime DELs against Wohler coefficients, which are fatigue ductility exponents or gradients of a specific material S N curve.

Figure 5 depicts lifetime DELs of edge-wise blade root moment. There is a constant pattern among the four models for each Wohler coefficient in figure 5.

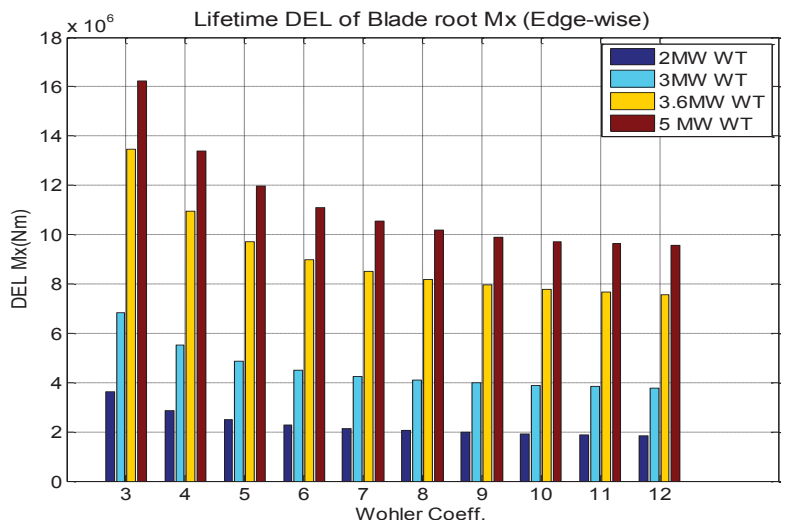

Figure 5: Lifetime DELs of edge-wise bending moment of blade root of four wind turbines

Flap-wise lifetime DELs of blade root moment is shown in figure 6, where there is general pattern among Wohler coefficients. Flap-wise DELs increases for higher Wohler coefficients apart from $3 \mathrm{MW}$ generic wind turbine.

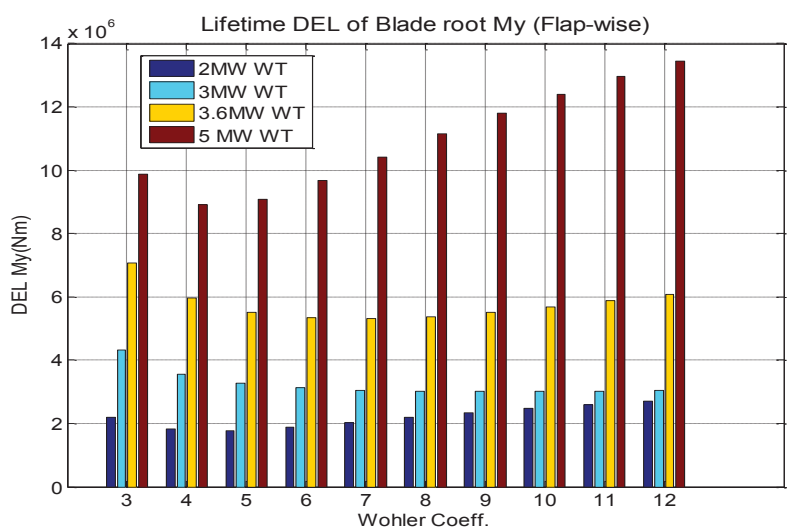

Figure 6: Lifetime DELs of flap-wise bending moment of blade root of four wind turbines

It has been proven that there a general trend of lifetime DELs among the four wind turbines (see figure 5 and 6)

\subsection{Deterministic Lifetime DELs}

This section investigates lifetime DELs of deterministic part of loads. The following two figures depict deterministic lifetime DELs of edge-wise and flap-wise blade root moments, respectively.

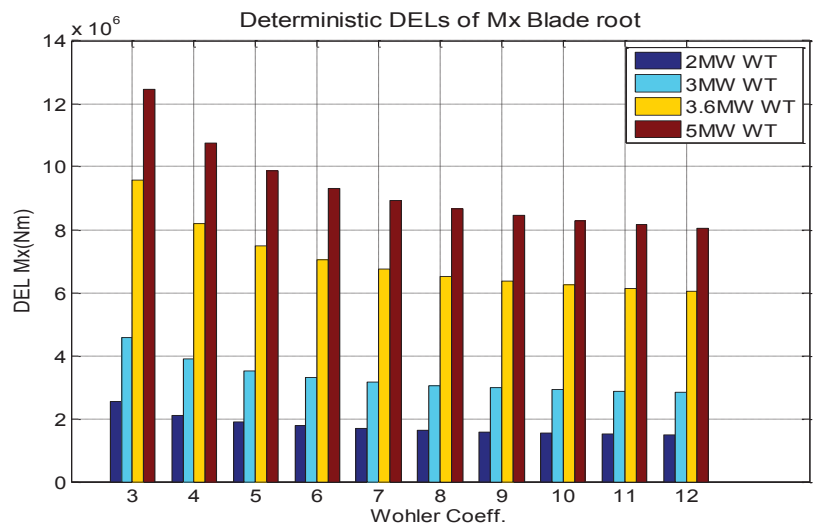

Figure 7: Deterministic lifetime DELs of edge-wise bending moment of blade root of four wind turbines

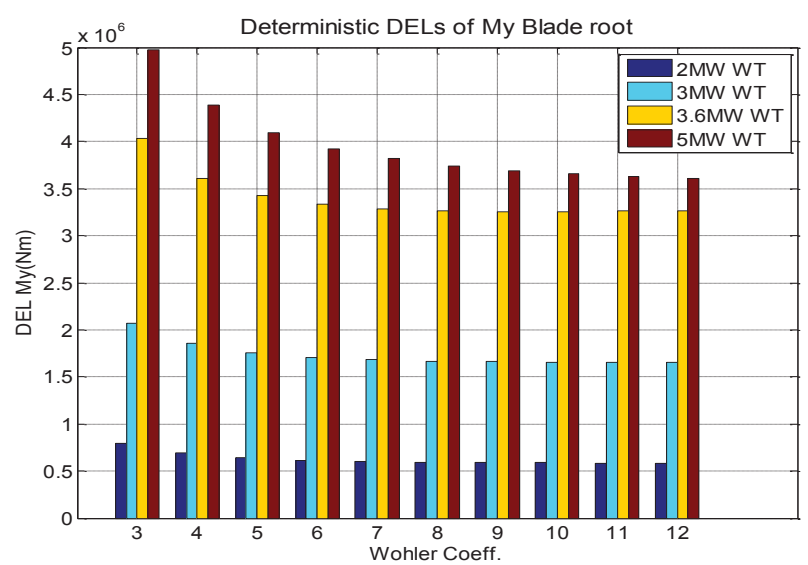

Figure 8: Deterministic lifetime DELs of flap-wise bending moment of blade root of four wind turbines

Figure 7 and 8 demonstrate a clear and consistent pattern of deterministic lifetime DELs among wind turbine models for each Wohler coefficients.

\subsection{Stochastic Lifetime DELs}

Stochastic lifetime DELs of edge-wise and flap-wise blade root moments are presented by the two following figures. There is a clear pattern of stochastic lifetime DELs of Wohler coefficient except $5 \mathrm{MW}$ wind turbine model in figure 9. 


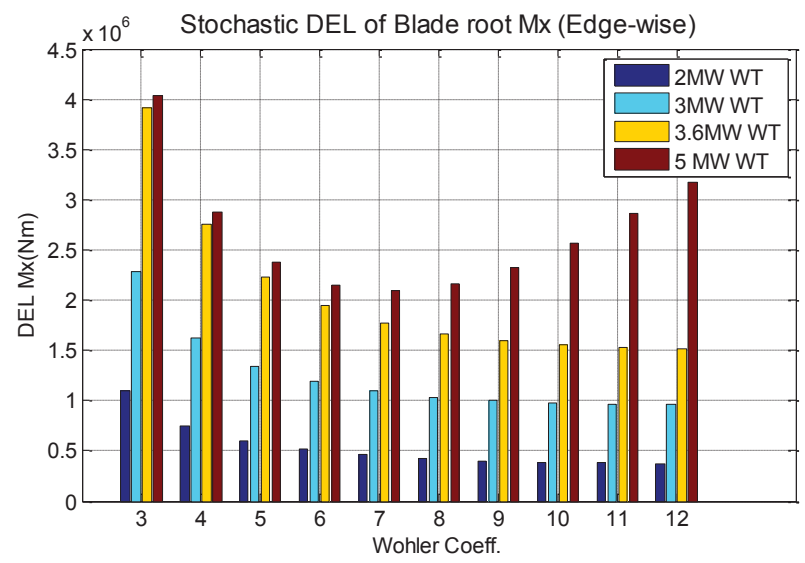

Figure 9: Stochastic lifetime DELs of edge-wise bending moment of blade root of four wind turbines

Figure 10 shows a general pattern among the three out of four wind turbine models at stochastic flap-wise moment DELs. The $3 \mathrm{MW}$ wind turbine model does not follow the general pattern.

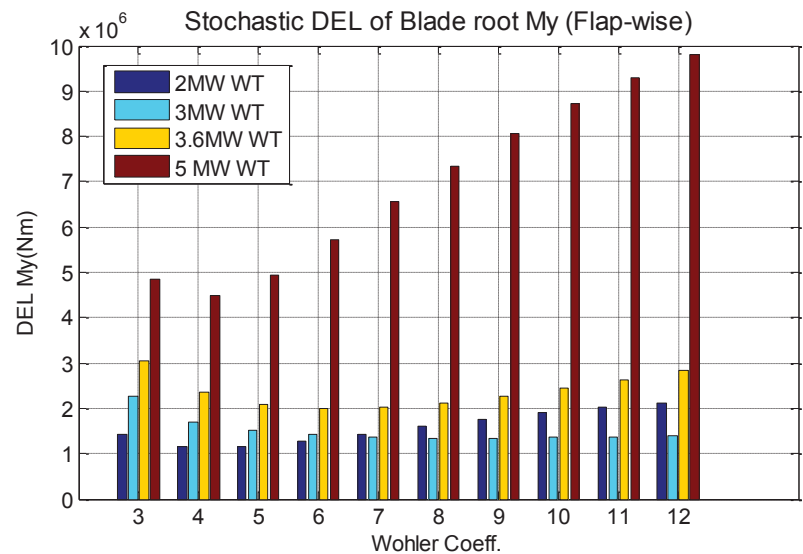

Figure 10: Stochastic lifetime DELs of flap-wise bending moment of blade root of four wind turbines

\subsection{Turbulence effect on Lifetime DELs}

In this section lifetime DELs of two different turbulence intensity levels are compared. Where, turbulence reference intensity was increased from 0.16 to 0.2 . In this section lifetime DELs did not split into stochastic and determinist parts, because the deterministic loading part does not depend on turbulence conditions. Only stochastic part of load depends on turbulence [10].

The turbulence effect is shown Wohler coefficients of 4 and 10 only to make figures easier to interpret. These Wohler coefficients relate steel and composite material, respectively. Figure 11 and 12 depicts lifetime DELs of edge-wise and flap-wise blade root moment respectively.

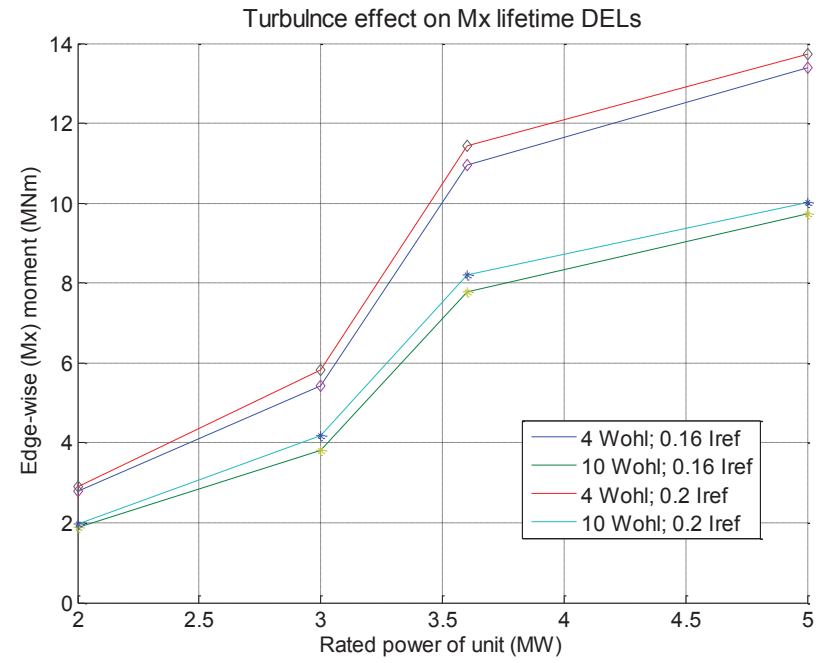

Figure 11: Lifetime DELs of edge-wise bending moment of blade root for Wohler coefficients of 4 and 10

Figure 11 shows an increase in lifetime DELs due to higher turbulence level for both Wohler coefficients. Fatigue loads increased more for the $5 \mathrm{MW}$ wind turbine compared to the 2 MW machine.

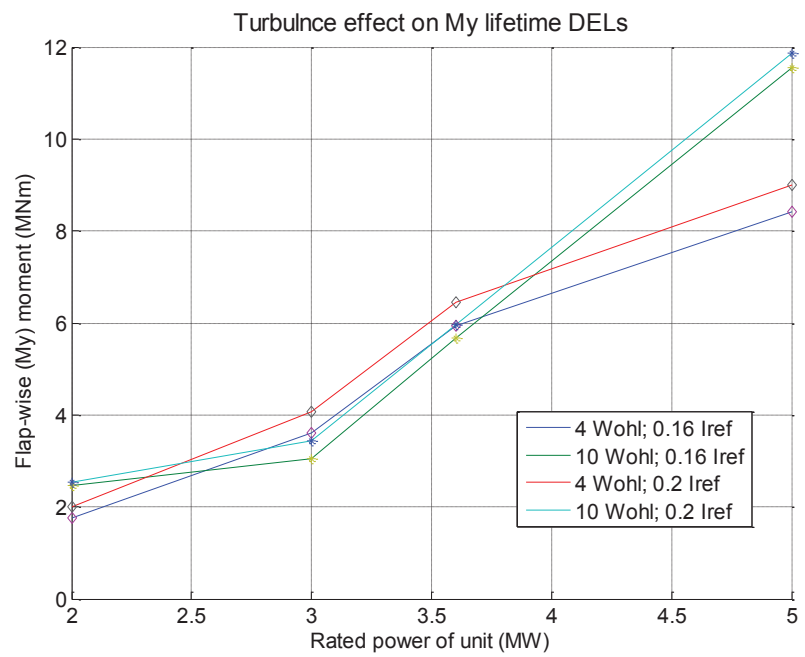

Figure 12: Lifetime DELs of flap-wise bending moment of blade root for Wohler coefficients of 4 and 10

Fatigue loads of flap-wise moment also go up due to higher turbulence. The increasing of fatigue loads is stronger for Wohler coefficient 4 (steel) than Wohler coefficient 10 (composite materials).

The two tables provide information how lifetime DELs increased the edge-wise and flap-wise bending moment for each wind turbine due to higher turbulence reference intensity. 


\begin{tabular}{|c|c|c|c|c|c|c|c|c|c|c|}
\hline $\begin{array}{l}\text { Wohler } \\
\text { minal Coeff. } \\
\text { wer of WT }\end{array}$ & $\underline{3}$ & $\underline{4}$ & $\underline{5}$ & $\underline{6}$ & $\underline{7}$ & $\underline{8}$ & $\underline{9}$ & $\underline{10}$ & $\underline{11}$ & $\underline{12}$ \\
\hline $2 \mathrm{MW}$ & $4.09 \%$ & $4.03 \%$ & \begin{tabular}{|l}
$4.14 \%$ \\
\end{tabular} & $4.26 \%$ & $4.40 \%$ & $4.50 \%$ & \begin{tabular}{|l}
$4.72 \%$ \\
\end{tabular} & $4.84 \%$ & $5.05 \%$ & $5.18 \%$ \\
\hline $3 \mathrm{MW}$ & $7.24 \%$ & $6.92 \%$ & $7.11 \%$ & $7.43 \%$ & $7.83 \%$ & $8.25 \%$ & $8.65 \%$ & $9.05 \%$ & $9.47 \%$ & $9.83 \%$ \\
\hline $3.6 \mathrm{MW}$ & $4.45 \%$ & $4.29 \%$ & $4.41 \%$ & $4.64 \%$ & $4.86 \%$ & $5.08 \%$ & $5.29 \%$ & $5.51 \%$ & $5.73 \%$ & $5.92 \%$ \\
\hline $5 \mathrm{MW}$ & $2.52 \%$ & $2.46 \%$ & $2.51 \%$ & $2.61 \%$ & $2.56 \%$ & $2.65 \%$ & $2.79 \%$ & $2.90 \%$ & $2.98 \%$ & $3.09 \%$ \\
\hline
\end{tabular}

Table 2: Increase of lifetime DELs of Edge-wise blade root moment due to higher turbulence

Table 2 demonstrates that the higher turbulence has more impact onto higher Wohler coefficients, which relate to composite materials.

\begin{tabular}{|c|c|c|c|c|c|c|c|c|c|c|}
\hline $\begin{array}{l}\text { Wohler } \\
\text { minal } \\
\text { wer of WT }\end{array}$ & $\underline{3}$ & $\underline{4}$ & $\underline{5}$ & $\underline{6}$ & I & $\underline{8}$ & $\underline{9}$ & $\underline{10}$ & $\underline{11}$ & $\underline{12}$ \\
\hline $2 \mathrm{MW}$ & $16.51 \%$ & $13.64 \%$ & $9.97 \%$ & $6.50 \%$ & $4.43 \%$ & $3.45 \%$ & $3.05 \%$ & $2.79 \%$ & $2.62 \%$ & $2.55 \%$ \\
\hline $3 \mathrm{MW}$ & $13.85 \%$ & $12.44 \%$ & $12.05 \%$ & $11.97 \%$ & $12.02 \%$ & $12.08 \%$ & $12.14 \%$ & $12.20 \%$ & $12.25 \%$ & $12.30 \%$ \\
\hline $3.6 \mathrm{MW}$ & $9.37 \%$ & $8.54 \%$ & $8.19 \%$ & $7.83 \%$ & $7.26 \%$ & $6.58 \%$ & $5.82 \%$ & $5.17 \%$ & $4.67 \%$ & $4.36 \%$ \\
\hline $5 \mathrm{MW}$ & $8.85 \%$ & $6.79 \%$ & $5.08 \%$ & $3.85 \%$ & $3.22 \%$ & $3.01 \%$ & $2.83 \%$ & $2.77 \%$ & $2.81 \%$ & $2.78 \%$ \\
\hline
\end{tabular}

Table 3: Increase of lifetime DELs of flap-wise blade root moment due to higher turbulence

Table 3 shows that the increase in turbulence intensity is more severe for low numbers of Wohler coefficients for flap-wise blade root moments. This is the opposite to what was seen for the edge-wise DELs

\section{Conclusion}

The goal of this paper was to investigate how hub loads differ among the four wind turbines, where the smallest and largest machines were $2 \mathrm{MW}$ and $5 \mathrm{MW}$. The source of hub loads are the blade loads. In this case the blade root loads were investigated, in particular edge-wise and flap-wise bending moment of blade root.

Power spectral density graphs of edge-wise and flap-wise bending moments showed that the frequencies of rotor and structural modes decrease with wind turbine size.

There is clear pattern of edge-wise lifetime DELs for each Wohler coefficients. In flap-wise lifetime DELs there is general pattern. In deterministic section edge-wise and flapwise lifetime DELs have a clear and consistent pattern among Wohler coefficients. Stochastic edge-wise lifetime DELs has the constant pattern among three wind turbine models, but 5 MW wind model does not follow the pattern. It is the same situation for the stochastic flap-wise lifetime DELs, where $3 \mathrm{MW}$ model does not match the general pattern of the stochastic flap-wise lifetime DELs.

The turbulence effect was studied for four wind turbine models by edge-wise and flap-wise lifetime DELs. It showed that increased turbulence effects both lifetime DELs (flapwise and edge-wise), but in the opposite manner. As it has more severe influence onto low Wohler coefficients at flapwise bending moment, and vice versa for edge-wise lifetime DELs bending moment.

\section{Acknowledgements}

The authors would like to thank EPSRC for the financial support and their industrial sponsor, DNV GL Energy for support in general guidance and use of Bladed software.

\section{References}

[1] P. K. Chaviaropoulos. "Similarity rules for wind turbine upscaling”. Internal report, Upwind.,(2007)

[2] P. Jamieson, "Loading and cost trends using certification calculation". Internal report, Upwind ,(2007)

[3] Martin O. L. Hansen Aerodynamics of Wind Turbines, 2nd edition, 2007

[4] P. Ragan, L. Manuel. "Comparing Estimates of Wind Turbine Fatigue Loads using Time-Domain and Spectral Methods", WIND ENGINEERING, volume 31, pp. 8299, (2007).

[5] H.B. Hendriks, B.H. Bulder . "Fatigue Equivalent Load Cycle Method". 1995

[6] International Standard IEC 61400-1 Wind turbines Part 1: Design requirements. 3rd edition 2008

[7] G. Genet. "A statistical approach to multi-input equivalent fatigue loads for the durability of automotive structures". Phd Thesis. 2006

[8] Jamieson, P. "Innovation in Wind Turbine Design", John Wiley \& Sons, 2011

[9] B. Maples, G. Saur, and M. Hand "Installation, Operation, and Maintenance Strategies to Reduce the Cost of Offshore Wind Energy" Technical Report 2013

[10] R. Kazacoks, P. Jamieson "A systematic hub loads models of a horizontal wind turbine" Torque conference 2014 